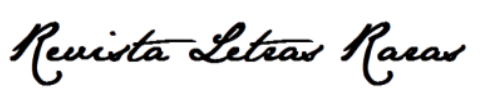

ISSN: 2317-2347 - v. 9, n. 4 (2020)

Todo o conteúdo da RLR está licenciado sob Creative Commons Atribuição 4.0 Internacional

\title{
Grassou e Frenhofer: obra-prima conhecida ou desconhecida? ${ }^{1}$
}

\author{
Grassou et Frenhofer: chef-d'œuvre connu ou inconnu?
}

\section{Izabel Dal Pont *}

Mestre em Literatura pela Universidade Federal de Santa Catarina (2019). Graduada em Letras Francês pela Universidade Federal de Santa Catarina (2017). Especialista em Tecnologia de Informação e Gestão Empresarial pela Pontifica Universidade Católica de Minas Gerais (1996). Graduada em Administração pela Universidade Federal de Santa Catarina (1990). Pesquisadora especialista em telecomunicações com atuação no Sistema Telebrás, GVT, Embratel (1979-2005). Experiência na área de Letras, com ênfase em Literatura atuando principalmente nos seguintes temas: escritura e pintura. Revisora de textos traduzidos do francês e do italiano.

\section{Marilene do Espirito Santo **}

Graduação em Física - Licenciatura pela Universidade Federal de Santa Catarina (1988), graduação em Direito pela Universidade do Vale do Itajaí (2001), especialização em Direito Civil e Processual Civil pela Faculdade CESUSC (2006), especialização em Direito Processual Penal pela Universidade do Vale do Itajaí (2006), mestrado pelo Programa de Mestrado em Ciência Jurídica da Universidade do Vale do Itajaí (2010), na área de concentração Fundamentos do Direito Positivo, Professora de Direito Penal na Universidade do Vale do Itajaí (2003-2013), graduanda em Letras- Francês na Universidade Federal de Santa Catarina, Advogada.

https://orcid.org/0000-0002-3752-5228

\section{Alain-Philippe Durand ${ }^{* * *}$}

Ph.D., University of North Carolina at Chapel Hill, 1999, Professor of French, Honors College Distinguished Fellow, Affiliated Faculty in Africana Studies, Latin American Studies, LGBT Studies, and Public and Applied Humanities at the University of Arizona. Former Interim Head of the Department of French and Italian (2015-2016), Director of the School of International Languages, Literatures, and Cultures (SILLC) (2010-2016), and Director of Africana Studies, (2011-2016).

Recebido: 16 mai. 2020. Aprovado: 10 out. 2020.

\footnotetext{
1 Este texto foi publicado pela primeira vez em língua francesa, por Alain-Philippe Durand, com o título "Grassou et Frenhofer: chef-d'œuvre connu ou inconnu?", em 1997.
}

Izabel.dalpont@icloud.com

$* *$

e.santo.mari@gmail.com

apdemarseille@gmail.com 


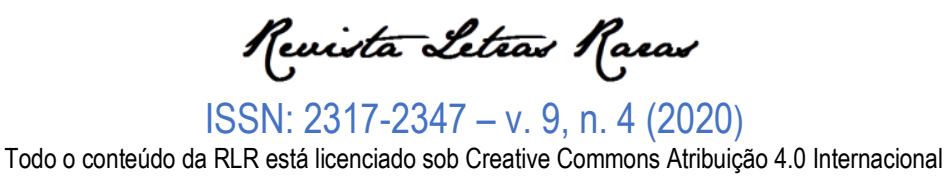

\section{Como citar esta tradução:}

DURAND, Alain-Philippe; DAL PONT, Izabel; ESPIRITO SANTO, Marilene. Grassou e Frenhofer: obra-prima conhecida ou desconhecida?. Revista Letras Raras. Campina Grande, v. 9, n. 4, p. 303-317, dez. 2020.

Le Chef-d'œuvre inconnu e Pierre Grassou se opõem, mas se completam. Grassou, diante do formidável Frenhofer, do demiurgo, representa "[...] o artista dos burgueses ou ainda o homem respeitável, execrável artista" (MEININGER, 1977, p. 1079). É então o problema de identidade artística e sua percepção social que se coloca nestes dois romances escritos com um intervalo de sete anos. Assim, Grassou-Fougères é um pintor popular entre os burgueses para os quais ele "copia" os retratos, tendo plena consciência de sua mediocridade criativa. Em oposição, Frenhofer se impõe desde logo como prisioneiro de sua pintura. Ele se vê condenado a uma constante e extenuante busca do ideal absoluto, o que o aproxima da loucura. Grassou e Frenhofer são vítimas de suas condições. 0 primeiro sabe que, apesar de seu sucesso no mundo material, não terá jamais este toque mágico que distingue 0 verdadeiro artista do simples copista. O segundo representa 0 artista genial vítima de uma monomania 2 suicida, a qual é incapaz de dominar. Ambos são o símbolo da distância terrível que separa a ambição da sua realização.

Nas múltiplas análises consagradas à Le Chef-d'œuvre inconnu, a crítica se debruça frequentemente sobre uma possível relação existente entre Balzac e seus personagens fictícios, ao invés de se concentrar apenas no artista. Por exemplo, Gretchen Besser afirma que Balzac se projeta através de todos os seus gênios (Frenhofer, Gambara, Claës, etc.) pois, como eles, se pretende um inventor cujo objetivo é atingir o inédito e o original (BESSER, 1969, p. 195). Maurice Beebe partilha da mesma abordagem do texto. Depois de ter comparado Balzac a todos os artistas de A Comédia humana, ele conclui que "it perhaps Vautrin who best represents Balzac's own nature as a creative artist"3 (BEEBE, 1960, p. 241).

Além disso, se Le Chef-d'œuvre inconnu continua a inspirar bom número de estudos, o romance Pierre Grassou permanece praticamente ignorado dos pesquisadores. De fato, dentre os poucos comentários existentes sobre o texto, a maioria demonstra um certo tom de superficialidade, ou mesmo de desdém. Assim, segundo Olivier Bonard, Pierre Grassou não é mais do que "um simples jogo de estilo", perfeita ilustração da caricatura a qual Balzac se apropria para "[...] esquecer por instantes as altas ambições de A Comédia humana [...]" (BONARD, 1969, p. 133). Por outro lado, em sua introdução à Pierre Grassou, Maurice Bardèche qualifica o romance de "bonne action" que dá "a impressão de uma

\footnotetext{
2 Retomo aqui a expressão que Gretchen Besser desenvolve em sua obra Balzac's Concept of Genius (1969. p. 77).

3 "talvez seja Vautrin quem melhor represente a natureza de Balzac como artista criativo."
} 


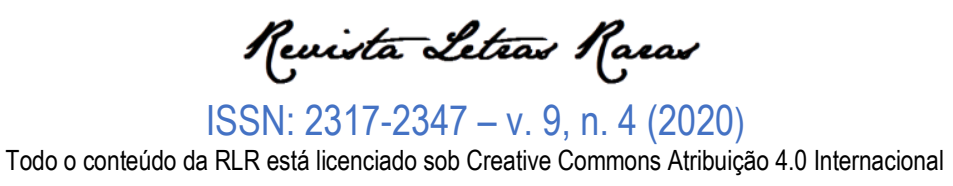

narrativa escrita rapidamente, pouco corrigida [...] sem que nada a ligue ao conjunto da obra de Balzac" (BARDÈCHE, 1969, p. 70).

No entanto, este texto de 1839 retoma vários temas da obra Le Chef-d'œuvre inconnu escrita em 1832, como por exemplo, o problema da percepção e da estética artística como uma questão de escolha. De fato, com Pierre Grassou, Balzac efetua uma desconstrução do artista em busca do ideal que ele criou em Le Chef-d'œuvre inconnu. Os dois pintores evoluem em um contexto social idêntico seguindo destinos opostos. Além do mais, é necessário notar que em Pierre Grassou, além da questão da Arte, o que mais importa é o homem e sua identidade de artista, em comparação aos seus pares e à sociedade:4

${ }^{5}$ Entre esses nomes, o mais desconhecido talvez seja aquele de um artista denominado Pierre Grassou, vindo de Fougères, chamado simplesmente Fougères no mundo artístico, o qual tem atualmente importante lugar ao sol, e sugere amargas reflexões por meio das quais começa o esboço de sua vida, extensível à quaisquer outros indivíduos da tribo dos artistas ${ }^{6}$ (BALZAC, 1977, p. 1092-93).

Balzac volta, sete anos mais tarde, ao tema Le Chef-d'œuvre inconnu, não para invocar o problema da obra de arte, mas sim aquele, bem mais difundido, do pintor desconhecido 7 . Enfim, podendo parecer caricatural e simplista numa primeira abordagem, a estrutura de Pierre Grassou se revela ainda mais complexa. De fato, este romance é bem mais significativo do que quer dizer uma grande parte da crítica. O objetivo deste estudo é, assim, demonstrar a importância deste texto, especialmente frente ao Le Chef-d'œuvre inconnu.

É justamente colocando em oposição Pierre Grassou e Le Chef-d'œuvre inconnu, que será abordada a questão do artista e sua representação nos dois romances de Balzac, a fim de demonstrar suas diferenças na concepção artística e também suas complementaridades. Neste sentido, é útil começar com a definição de arte segundo Grassou e Frenhofer. Aliás, é importante destacar a diferença fundamental de identidade que aparece entre os dois pintores. Além disso, uma análise dos personagens, de suas interações e de seus comportamentos demonstrará como os protagonistas de cada história exercem um papel preponderante na valorização do artista. Serão abordados também os

\footnotetext{
${ }^{4}$ Este argumento parece partilhado por André Wurmser, um dos raros críticos a ter adivinhado o verdadeiro alcance de Pierre Grassou. Ele escreve que "é ao amante dos homens e não ao amante da arte que se deve atribuir uma das pequenas joias de A Comédia humana, Pierre Grassou" (1970, p. 410).

5 Todas as citações de trechos de obras de Balzac são de nossa autoria.

6 "Parmi ces noms, le plus inconnu peut-être est celui d'un artiste nommé Pierre Grassou, venu de Fougères, appelé plus simplement Fougères dans le monde artiste, qui tient aujourd'hui beaucoup de place au soleil, et qui suggère les amères réflexions par lesquelles commence l'esquisse de sa vie, applicable à quelques autres individus de la Tribu des Artistes." Todas as traduções de excertos das obras Pierre Grassou, Le Chef-d'œuvre inconnu e das demais obras de Balzac são de nossa autoria.

7 Murray Sachs gentilmente sugeriu este indício.
} 


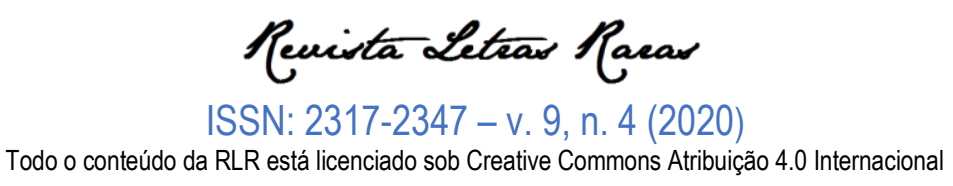

temas comuns às duas obras examinando a maneira segundo a qual Balzac os desenvolve. Finalmente, uma exploração aprofundada dos pintores e dos quadros verdadeiros dos quais se serve o autor em Pierre Grassou revelará uma verdadeira hierarquia do plágio escondido por trás do texto fictício.

A oposição basilar entre a arte de Frenhofer e aquela de Pierre Grassou se encontra na diferença que existe entre o homem de gênio e o homem material. Enquanto que para Frenhofer "a missão da arte não é copiar a natureza, mas exprimi-la"8 (BALZAC, 1981, p. 48), segundo Grassou, "criar en toute chose, é morrer lentamente, copiar é viver"g (BALZAC, 1977, p. 1101). Assim, de acordo com Frenhofer, a função da arte não sofre nenhuma ambiguidade: seu papel consiste na procura de um belo absoluto e de um ideal natural. 0 pintor deve perseverar "até que a natureza se mostre toda nua e em seu verdadeiro espírito"10 (BALZAC, 1981, p. 49).

De fato, Frenhofer representa o gênio no estado puro. A sua capacidade criativa é tão poderosa que não existe pincel capaz de refletir toda a sua envergadura. Além disso, ele é apresentado como um "ser sobrenatural"11 (BALZAC, 1981, p. 56), um homem cuja força criativa ultrapassa a sua condição humana. Essa superabundância de qualidades o leva a uma obsessão monomaníaca na qual a loucura termina por se misturar à genialidade. No arrebatamento de sua inspiração devastadora, acreditando ter sido lançado nos meandros do absoluto ele ultrapassa seu próprio gênio para atingir "un pâté de couleur claire" (BALZAC, 1981, p. 70) à despeito da Belle Noiseuse anunciada. Seus esboços, verdadeiras obrasprimas aos olhos de Poussin e Porbus, são para apenas simples etapas na busca de um absoluto no qual ele acredita, mas que permanecerá irremediavelmente utópico. Não há o que fazer com uma celebridade que ele sequer procura. O que mais conta na vida para este artista é "ver um momento, uma só vez, a natureza divina, completa, o ideal enfim"12 (BALZAC, 1981, p. 57). Ele ironiza a noção de tempo que, segundo ele, não pode imobilizar a sua luta com a natureza (BALZAC, 1981, p. 56).

Ademais, no que diz respeito a Frenhofer, para que a arte não se limite unicamente à uma questão de aparência, de beleza representada, é necessário colocar em destaque na pesquisa criativa este "ce je ne sais quoi' que é, talvez, a alma"13 (BALZAC, 1981, p. 50). A arte não deve se limitar ao desenho e à cor, mas deve antecipá-los e amplificá-los, dando-lhes pelo viés do sentimento (BALZAC, 1981, p. 50), uma fisionomia e um espírito que tornem a obra "viva". É preciso igualmente notar que esta visão da arte

\footnotetext{
8 "La mission de l'art n'est pas de copier la nature, mais de l'exprimer !"

9 "Inventer en toute chose, c'est vouloir mourir à petit feu ; copier, c'est vivre."

10 "[...] jusqu'à ce que la nature en soit réduite à se montrer toute nue et dans son véritable esprit."

11 Nota-se que 0 adjetivo "sobrenatural" reaparece diversas vezes no texto referindo-se à Frenhofer.

12 "voir un moment, une seule fois, la nature divine, complète, l'idéal enfin, [...]"

13 "[...] ce je ne sais quoi qui est l'âme peut-être [...]"
} 


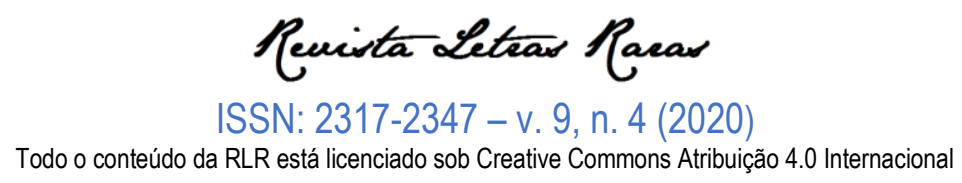

absoluta não pode ser entendida sem um certo misticismo. Efetivamente, parece que o artista genial, em sua inspiração, é tocado ou mesmo guiado pela mão de Deus:

toda figura é um mundo, um retrato no qual o modelo apareceu em uma visão sublime, tingido de luz, designado por uma voz interior, desnudado por um dedo celeste, que mostrou no passado de toda uma vida, as fontes da expressão ${ }^{14}$ (BALZAC, 1981, p. 49).

Se a concepção de arte de Frenhofer o transporta para além da razão, Pierre Grassou se encontra no estado de espírito inverso. Ele tem consciência de sua falta de genialidade, motivo pelo qual ele sofre constantemente. Ele não é "importunado nem por esta abundância de sangue, nem por esta violência de pensamentos, nem por esta veia cômica através da qual se reconhecem os grandes artistas"15 (BALZAC, 1977, p. 1096), e especialmente Frenhofer. De fato, Grassou se apresenta antes de tudo como um pintor material que "não sai de um círculo burguês onde é considerado um dos maiores artistas da época"16 (BALZAC, 1977, p. 1111). Nota-se aqui um conflito muito importante na base da definição de arte absoluta que Balzac dá através de seus dois pintores. Assim, Frenhofer ultrapassa seu próprio gênio e, querendo tocar 0 absoluto, perde irremediavelmente o contato com sua tela que se torna totalmente ilegível aos olhos de seus discípulos. Ao querer tocar o ideal, Frenhofer se lança em uma busca ao mesmo tempo suicida e incontrolável, e ultrapassa o ponto de não retorno. Ele se torna inconsciente, persuadido de ter enfim restaurado o absoluto. A partir de então é impossível que Poussin e Porbus possam distinguir o que quer que seja neste acúmulo de pintura. Por ter desejado alcançar a graça universal, Frenhofer deve pagar com sua vida esta loucura, a morte restando como a única saída possível a fim de preservar o Eidos utópico. Frenhofer permanece incompreendido ao mais comum dos mortais porque ele quer muito que sua pintura se aproxime do ideal, uma noção inatingível para o espírito humano.

Em contrapartida, Grassou obtém imenso sucesso junto à burguesia pintando telas tão banais quanto ele. Além disso, encontra a glória apresentando no Louvre La Toilette d'un chouan, condamné à mort en 1809, uma obra fortemente inspirada em Dow (sic) ${ }^{17}$ que "tinha como fazer tremer os burgueses, que de fato tremiam"18 (BALZAC, 1977, p. 1100). Em seguida, o pintor medíocre, porém cada vez mais

\footnotetext{
14 "Toute figure est un monde, un portrait dont le modèle est apparu dans une vision sublime, teint de lumière, désigné par une voix intérieure, dépouillé par un doigt céleste qui a montré, dans le passé de toute une vie, les sources de l'expression."

"15 "[...] tourmenté ni par cette abondance de sang, ni par cette violence de pensée, ni par cette verve comique à laquelle se reconnaissent les grands artistes.

16 "[...] ne sort pas d'un cercle bourgeois où il est considéré comme un des plus grands artistes de l'époque, [...]"

17 Balzac parece ter utilizado a ortografia inglesa do nome do pintor Gerard Dou.

18 "....] avait de quoi faire frémir les bourgeois, et les bourgeois frémissaient."
} 


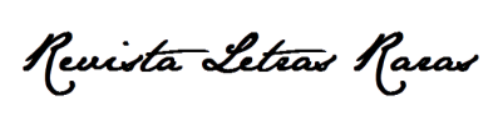

ISSN: 2317-2347 - v. 9, n. 4 (2020)

Todo o conteúdo da RLR está licenciado sob Creative Commons Atribuição 4.0 Internacional

popular, fornece uma sequência de retratos burgueses nos quais se sobressai "com uma regularidade desesperadora"19 (BALZAC, 1977, p. 1101). Os sentidos não exercem nenhum papel na arte de Grassou. Segundo o copista inveterado, a pintura se resume a uma reprodução fiel, não do ideal, mas da aparência física dos modelos. Com as representações da mãe e da filha Vervelle (BALZAC, 1977, p. 1103) temos uma ideia exata do que pinta Pierre Grassou. Não é o olho de um artista que faz esta descrição, mas o olho de Grassou, aquele que faz cópias. Trata-se de uma oposição radical às proezas criativas de Frenhofer. Grassou se contenta em colocar na tela "legumes" (BALZAC, 1977, p. 1103) enquanto que o velho gênio atribui sentidos iluminando as telas de ninfas nas quais "o corpo gira, as formas se projetam, e se sente 0 ar circular ao redor de tudo"20 (BALZAC, 1981, p. 55).

Consequentemente, ao contrário de Frenhofer, gênio e, ao mesmo tempo, inconsciente de sua loucura e incompreendido por seus pares, Grassou é apenas um excelente plagiador, de fato consciente de sua mediocridade mesmo que aproveitando de um renome sem limite no seio da burguesia. Grassou é o elemento indispensável nesta oposição que funciona como um espelho invertido. Balzac estabelece a diferença entre o que é belo e o que se vende. Segundo ele, somente 0 artista de talento pode se lançar na busca do ideal absoluto. É com esta ambição que seu gênio se desenvolve e atinge seu apogeu. Todavia, ele é condenado a ultrapassar esta etapa pois, não podendo se impedir de acariciar o intocável, continua sua busca até perder a razão. Observa-se esse itinerário em Le Chef-d'œuvre inconnu quando Poussin e Porbus percebem que o que Frenhofer chama de simples esboços, são em realidade verdadeiras obras-primas (BALZAC, 1981, p. 68). Parece então evidente que na hierarquia universal que Balzac edifica, o ideal da beleza absoluta ocupa um topo inviolável. 0 artista genial obtém o direito de ser classificado de acordo com esta hierarquia, apesar do absurdo da sua luta solitária. Independentemente de serem chamados Frenhofer, Gambara ou Balthasar Claës, os gênios balzaquianos são destinados ao fracasso pois se 0 absoluto fosse descoberto, sua noção inteira, na origem da criação artística, não teria mais sentido e a ordem universal seria alterada.

A burguesia não compartilha a mesma definição de beleza absoluta. De acordo com o burguês, a obra de arte deverá remeter à imagem da conquista social. Ali está a razão do sucesso de Pierre Grassou que copia admiravelmente os retratos de "Monsieur tout le monde". O burguês não se interessa pela inspiração espontânea, o que ele quer é reprodução fiel de sua condição e não as excentricidades ligadas à genialidade do artista. Quando os Vervelle chegam ao atelier de Grassou (BALZAC, 1977, p. 1103), eles parecem mais interessados pela vida organizada e pelas instalações deste "honesto artista"

19 "[...] avec une régularité désespérante"

20 "[...] le corps tourne, les formes deviennent saillantes, l'on sent l'air circuler tout autour" 


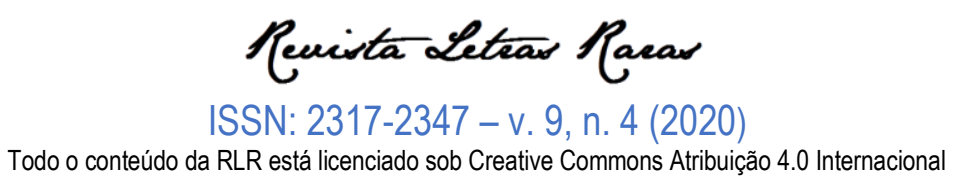

(BALZAC, 1977, p. 1094) que por suas qualidades de pintor. A paciência e a polidez espontâneas de Grassou são interrompidas pela chegada da "besta feroz" (BALZAC, 1977, p. 1108) Joseph Bridau naquele "local limpo, cuidado, agradável, artístico"21. (BALZAC, 1977, p. 1106). Esse artista desenvolto possui o domínio e a liberdade de expressão, com os quais Pierre Grassou sempre sonhou, sem jamais conseguir alcançar. A aparição de Bridau se encontra no excerto no qual a distinção entre as duas faces destes artistas é mais flagrante. Grassou tenta explicar que esta "tempestade" sopra apenas sobre os pintores geniais, mas a senhora Vervelle rapidamente o faz lembrar da ordem burguesa declarando, no que diz respeito ao intruso, que "se é um grande artista, eu prefiro o grande artista que se pareça com você"22 (BALZAC, 1977, p. 1108). Esta intervenção reverberou como um som lúgubre para Grassou, para quem a última tentativa junto à genialidade fracassou. Não somente ele teve a certeza do seu não pertencimento ao grupo dos criadores, como também, de ter sido confirmado na classe dos Vervelle.

Para esses últimos, a noção da arte se limita a uma boa imitação que a ela remete. Uma vez que Pierre Grassou reconhece suas cópias de mestres na galeria de Vervelle, longe de se indignar este último responde: "prove-me [...] e eu dobro o dote de minha filha, pois então você é Rubens, Rembrandt, Terburg, Titien!"23 (BALZAC, 1977, p. 1110). Assim, esse homem que acredita que uma cópia é tão boa quanto a obra original, não vê senão 0 aspecto financeiro da situação. $A$ arte se torna então um investimento para o qual se pode fixar o preço. Trata-se de um aspecto importante do romance que Balzac tem prazer em desenvolver. Nota-se, então, que a arte não tem preço em Le Chef-d'œuvre inconnu, romance no qual a noção de valor monetário e de investimento não aparece jamais. Em Pierre Grassou, muitos aspectos financeiros caminham lado a lado com o plágio artístico. Para começar, Grassou coloca seu dinheiro cautelosamente junto a um contador e vende regularmente, quase em série, reproduções aos seus clientes (a corte e os Vervelle) e ao seu fornecedor Elias Magus. Além do mais, a denominação "marchand de tableaux" em referência a esse último aparece frequentemente na narrativa. Logo, Pierre Grassou trata o artista como um funcionário localizado no centro de uma transação comercial entre um "marchand de tableaux" (Elias Magus) e um "marchand de bouteilles" (Vervelle). 0 romance é repleto de termos financeiros, mencionando num estilo muito balzaquiano o detalhe das somas pagas. Entre os numerosos exemplos que a narrativa apresenta, duas passagens permanecem como as mais características desse comércio de arte. Relembra-se aqui o diálogo entre Pierre Grassou e Elias Magus quando da apresentação da família Vervelle:

\footnotetext{
21 "[...] ce local propre, soigné, gentil, artiste."

22 "- - Si c'est un grand artiste, j'aime mieux un grand artiste qui vous ressemble, [...]"

23 "- Prouvez-le-moi, [...] et je double la dot de ma fille, car alors vous êtes Rubens, Rembrandt, Terburg, Titien !"
} 


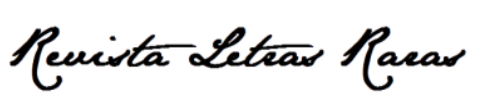

ISSN: 2317-2347 - v. 9, n. 4 (2020)

Todo o conteúdo da RLR está licenciado sob Creative Commons Atribuição 4.0 Internacional

- Apenas você para pescar uns tipos como esses.

- Cem mil francos de dote!

- Sim; mais que família!

- Trezentos mil francos de esperança, casa na rua Boucherat e casa de campo na Ville-d'Avray.

- Boucherat, bouteilles, bouchons, bouchés, débouchés, disse o pintor.

- Você estará bem para o resto de seus dias, disse Elias²4 (BALZAC, 1977, p. 1104).

Neste trecho, as somas mencionadas vão crescendo como em um leilão. Magus desempenha 0 papel de vendedor que, para convencer seus clientes, não hesita em supervalorizar as somas dos benefícios por eles esperados. Diante da incerteza inicial de Grassou, Magus emprega grandes argumentos em sua derradeira réplica na qual ele concretiza o significado das cifras por meio de uma afirmação realista que ressoa na orelha do pintor como o trinco de um cofre-forte.

Observa-se igualmente a discussão entre Grassou e Vervelle no momento em que o pintor descobre suas telas na casa do burguês:

- Três mil francos! Diz em voz baixa Vervelle aproximando-se deste último; mas eu digo quarenta mil francos!

- Quarenta mil francos um Titien? Repete em voz alta o artista, mas isso seria por nada.

- Quando eu lhe dizia, eu tenho por volta cem mil écus em quadros, exclama Vervelle. - Eu pintei todos esses quadros, todos juntos não foram vendidos por mais de dez mil francos, sussurrou-lhe, ao pé do ouvido, Pierre Grassou [...] $]^{25}$ (BALZAC, 1977, p. 1110).

Além da conotação financeira anteriormente mencionada, este trecho se mostra interessante por seu paralelo entre as somas evocadas e o tom de voz dos protagonistas. De fato, a potência do tom dos dois homens aumenta (de "voz baixa" à "voz alta" e "exclamação") com o crescimento das somas. Assim que o montante recomeça a baixar, passando de "cem mil écus" à "dez mil francos", acontece o mesmo com a entonação.

Enfim, a noção artística destes dois pintores se opõe igualmente, no plano da sua encenação (sa mise en scène). Assim, como bem observou Chantal Massol-Bédoin, em Le Chef-d'œuvre inconnu, "é o segredo [...] que permite o mito do Artista de se construir e de funcionar" (MASSOL-BÉDOIN, 1986, p. 47). Isto se traduz no romance por um conflito entre o espaço conhecido e o espaço desconhecido 26.

\footnotetext{
24 " - II n'y a que vous pour pêcher de pareilles boules. — Cent mille francs de dot ! — Oui ; mais quelle famille ! — Trois cent mille francs d'espérances, maison rue Boucherat, et maison de campagne à Ville-d'Avray. — Boucherat, bouteilles, bouchons, bouchés, débouchés, dit le peintre. — Vous serez à l'abri du besoin pour le reste de vos jours, dit Élias." 25 " - Trois mille francs ! dit à voix basse Vervelle en arrivant au dernier ; mais je dis quarante mille francs ! - Quarante mille francs un Titien ? reprit à hante voix l'artiste, mais ce serait pour rien. — Quand je vous le disais, j'ai pour cent mille écus de tableaux s'écria Vervelle. - J'ai fait tous ces tableaux-là, lui dit à l'oreille Pierre Grassou, je ne les ai pas vendus tous ensemble plus de dix mille francs..."

${ }^{26}$ Aqui o título do romance assume toda sua grandeza
} 


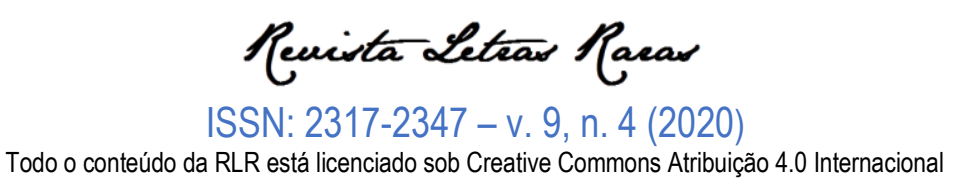

Desde o início, o jovem Poussin (e o leitor com ele) fica ao mesmo tempo intrigado e atraído por "esse não sei que (ce je ne sais quoi)" (BALZAC, 1981, p. 44) que caracteriza Frenhofer. O velho pintor aparece ao aprendiz com um físico e vestimentas que dão tão-somente "uma imagem imperfeita deste personagem ao qual, além disso, a frágil iluminação da escada emprestava a ele uma cor fantástica"27 (BALZAC, 1981, p. 45). Esse último adjetivo deixa entrever um tesouro escondido por trás da face envelhecida. A curiosidade continua a crescer junto com a narrativa. Depois da sua chegada ao atelier de Porbus na companhia do velho pintor, a demonstração desse último e 0 jantar deles na casa do mestre, o jovem não conhecia ainda a sua identidade:

Poussin olhava alternadamente o velho pintor e Porbus com uma inquietante curiosidade. Ele se aproximou daquele como que para lhe perguntar o nome de seu hóspede; mas o pintor colocou o dedo sobre os lábios com ar de mistério, e o jovem, vivamente interessado, guardou o silêncio28 (BALZAC, 1981, p. 53-54).

De fato, o mestre jamais indicará sua identidade e é unicamente graças à Porbus que, em determinado momento, exclama "Mestre Frenhofer" (BALZAC, 1981, p. 54) que Poussin descobrirá o nome do gênio.

Apesar disso, a noção de segredo permanece, ultrapassando a questão da identidade do artista para alcançar a de sua obra prima, La Belle Noiseuse: "se você quiser me [a] deixar ver"29 (BALZAC, 1981, p. 54) declara Porbus. Esta intervenção representa o ponto de partida dos esforços que os dois jovens pintores fazem, com o objetivo de penetrar no atelier. $O$ fato de que velho mestre persiste em descrever os detalhes de seu quadro, o exaltando, reforça a curiosidade e o sentimento de mistério que aumenta nos dois jovens. O atelier, espaço conhecido somente por Frenhofer, enclausura La Belle Noiseuse, obra-prima desconhecida aos olhos de Poussin e Porbus. Estamos, então, diante de um local o qual conserva a representação mística e secreta da obra de arte. Assim que os dois pintores terminam por transpor este verdadeiro santuário, o segredo enfim revelado não é aquele que eles imaginavam. Ao invés de descobrir a beleza absoluta, eles se deparam com uma mistura incoerente de cores. 0 espaço desconhecido, o segredo do ideal, permanece então inviolado, porque somente Frenhofer, em sua loucura, consegue colocá-la em imagens.

Esta noção de espaço é tratada diferentemente em Pierre Grassou. Nesse romance, o atelier não tem nada de um local sagrado e, sobretudo, ele não esconde nenhuma obra de arte. Ao longo de toda a

\footnotetext{
27 "[...] une image imparfaite de ce personnage auquel le jour faible de l'escalier prêtait encore une couleur fantastique."

28 "Poussin regardait alternativement le vieillard et Porbus avec une inquiète curiosité. II s'approcha de celui-ci comme pour lui demander le nom de leur hôte ; mais le peintre se mit un doigt sur les lèvres d'un air de mystère, et le jeune homme, vivement intéressé, garda le silence [...]"

29 "[...] si vous vouliez me [la] laisser voir [...]"
} 


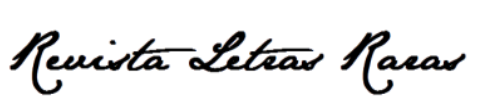

ISSN: 2317-2347 - v. 9, n. 4 (2020)

Todo o conteúdo da RLR está licenciado sob Creative Commons Atribuição 4.0 Internacional

narrativa, na rua Navarin assiste-se a um verdadeiro desfile de artistas (Schinner, Bridau), do comerciante Magus e dos burgueses Vervelle. De fato, ao contrário de Le Chef-d'œuvre inconnu, tudo aqui é conhecido, ou seja, identificável. Grassou pinta cópias para Magus e reproduz, em suas telas, retratos dos Vervelle. Mesmo a galeria dos burgueses expõe, somente, obras "conhecidas", visto que são cópias de grandes mestres feitas por Grassou. Em sentido inverso ao segredo que simboliza a Arte em Le Chef-d'œuvre inconnu ${ }^{30}$, é o plágio que constrói o mito do artista em Pierre Grassou.

Se a noção de arte, tal qual foi concebida por Frenhofer e Grassou, foi definida, é necessário agora se voltar para a fisionomia destes dois personagens. Parece, com efeito, que a morfologia do artista se mostra decisiva para Balzac, notadamente no que tange à diferenciação entre o gênio e o simples copista. Gretchen Besser sublinhou que o aspecto físico do homem balzaquiano é a fronte larga e a calvície (BESSER, 1969, p. 69). Sua tese se verifica em todos os "mestres" de A Comédia humana. 0 músico Gambara apresenta "uma fronte larga e calva [...] marcada por rugas paralelas e pouco profundas"31 (BALZAC, 1979, p. 469), enquanto a fronte larga do químico Balthazar Claës ${ }^{32}$ possui protuberâncias (BALZAC, 1976, p. 42). Acontece o mesmo no que se refere à aparência de Frenhofer que é descrito como um pintor de "fronte calva, arredondada, proeminente, projetando-se sobre um pequeno nariz achatado"33. Nota-se, igualmente, seus "olhos verdes da cor do mar" (BALZAC, 1981, p. 44) os quais se impõem pela ausência de cílios (BALZAC, 1981, p. 45).

Em contrapartida, Grassou aparece "roliço e de altura medíocre [...] a pele sem viço, os olhos castanhos, os cabelos pretos, o nariz aduncado, uma boca larga e orelhas longas"34 (BALZAC, 1977, p. 1096). Grassou não apresenta, então, as características físicas que Balzac parece reservar a seus gênios. Possui cabelos pretos e olhos castanhos, ou seja, sem cor. O narrador persegue o conflito entre a genialidade e a mediocridade até mesmo na caracterização morfológica de seus personagens.

A oposição entre os dois romances se mostra, igualmente, pela presença de temas comuns tratados diferentemente. A princípio, nota-se a importância da percepção. A noção de genialidade que domina Le Chef-d'œuvre inconnu representa uma visão que pode transpassar o objeto pintado para alcançar a Arte. Assim, Frenhofer vê além da mistura de cores de sua Belle Noiseuse. Porém é Gillette, a companheira de Poussin, quem dá o melhor exemplo da concentração genial do artista:

\footnotetext{
30 "Vocês se imaginam pintores e acreditam ter roubado o segredo de Deus" (BALZAC, 1982, p. 46).

31 "[...] un front large et chauve [...] sillonné de quelque plis parallèles et peu profonds [...]"

32 Herói de La Recherche de l'absolu.

33 "[...] front chauve, bombé, proéminent, retombant en saillie sur un petit nez écrasé [...]"

34 "[...] grassouillet et d'une taille médiocre, [...] le teint fade, les yeux bruns, les cheveux noirs, le nez en trompette, une bouche assez large et les oreilles longues."
} 


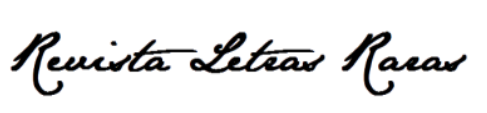

ISSN: 2317-2347 - v. 9, n. 4 (2020)

Todo o conteúdo da RLR está licenciado sob Creative Commons Atribuição 4.0 Internacional

- se tu desejas que eu pose mais uma vez diante de ti como no outro dia, ela repete, com um ar manhoso, eu nunca mais consentirei, pois nestes momentos, teus olhos não me dizem mais nada. Tu não pensas mais em mim, embora tu me olhes ${ }^{35}$ (BALZAC, 1981, p. 59).

Evidentemente, a visão de Pierre Grassou se afasta do artista para se aproximar do burguês. Assim que a família Vervelle chega ao seu atelier, Grassou não desdenha de seus "legumes" como 0 faria um "verdadeiro pintor". Ao contrário, "Fougères ${ }^{36}$ encara a prática sem rir, pois M. Vervelle portava em sua camisa um diamante de mil écus"37 (BALZAC, 1977, p. 1103). A percepção dos burgueses é dominada pela importância dada aos objetos e outros berloques reforçando 0 valor financeiro do indivíduo. O leitor capta rapidamente a ambição suprema de Grassou: "entrar no Instituto e [...] ter a roseta dos oficiais da Legião da Honra! [...] ingressar na Academia"38 (BALZAC, 1977, p. 1102). Então, entre beleza ideal e absoluta, Grassou escolheu a glória; entre a condição efémera e a indecisão do gênio, ele prefere o investimento à longo termo do banqueiro.

O lado material de Grassou se reflete na personalidade dos Vervelle com quem ele se entende: "abyssus abyssum" (BALZAC, 1977, p. 1106). Deste modo, tão logo Madame nota o pintor ela não consegue deixar de exclamar: "Vervelle, ele possui a cruz"39 (BALZAC, 1977, p. 1104)40. A arte se torna para esses "mascates" da criação uma opção para aumentar seu futuro patrimônio. Algumas técnicas narrativas reforçam esta imagem. Em um primeiro momento nota-se diversas frases com dupla conotação. Por exemplo, falando de seu dinheiro, Grassou declara à Madame Vervelle: "eu não gasto, eu não tenho meios para me divertir"41 (BALZAC, 1977, p. 1104). Isto significa que Grassou, não apenas não ganha dinheiro suficiente para esbanjar em divertimento, mas demostra também que a arte não é para ele um prazer e sim, acima de tudo, uma tarefa penosa, porém rentável. O pintor compartilha deste estado de espírito com Vervelle que lhe diz que "não se deve doar assim os seus quadros, isto é dinheiro"42 (BALZAC, 1977, p. 1106). Além disso, quando o burguês fala do valor dos seus cento e cinquenta quadros, ele não faz referência às suas qualidades artísticas, mas aos cem mil écus (BALZAC, 1977, p. 1110) que eles representam.

\footnotetext{
35 “- Si tu désires que je pose encore devant toi comme l'autre jour, reprit-elle d'un petit air boudeur, je n'y consentirai plus jamais, car, dans ces moments-là, tes yeux ne me disent plus rien. Tu ne penses plus à moi, et cependant tu me regardes."

${ }^{36}$ Ou seja, Grassou.

37 "Fougères regarda la pratique sans rire, car monsieur Vervelle présentait un diamant de mille écus à sa chemise."

38 "[...] entrer à l'Institut et [...] avoir la rosette des Officiers de la Légion [...] arriver à l'Académie"

39 "Vervelle, il a la croix [...]"

40 Esta informação, aliás, já foi mencionada anteriormente no romance cf. BALZAC, 1977. p. 1094

41 "[...] je ne le dépense pas, je n'ai pas le moyen de m'amuser."

42 "II ne faut pas donner ainsi vos tableaux, c'est de l'argent [...]"
} 


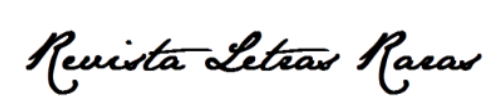

ISSN: 2317-2347 - v. 9, n. 4 (2020)

Todo o conteúdo da RLR está licenciado sob Creative Commons Atribuição 4.0 Internacional

Segundo os Vervelle, a Arte se traduz pela predominância da quantidade sobre qualidade. A narrativa impõe esta ideia ao insistir no suposto amor da família "pelas Artes". De fato, este conceito reaparece cinco vezes por meio de expressões idênticas. Esses burgueses são, a princípio, "loucos pelas artes" (BALZAC, 1977, p. 1094) antes que seus sentimentos sejam demonstrados no espaços de três páginas: "um ar de felicidade que anunciava neles um respeitável entusiasmo pelas Artes"43 (BALZAC, 1977, p. 1104), "porque você não me ensinou sobre as Artes?"; "além do mais nós amamos as Artes"44 (BALZAC, 1977, p. 1105) e "eu amo as Artes" (BALZAC, 1977, p. 1106). A utilização do plural e da maiúscula demonstra que, para os Vervelle, a arte não é uma estética ideal mas, sobretudo, uma acumulação de objetos, de quadros que garantem uma certa condição social.

Quanto à questão da escolha, ela está presente nos dois romances. Frenhofer, Poussin e Grassou tem em comum o dever de escolher entre a arte e o amor ${ }^{45}$. Se Frenhofer termina por perder a razão e morre no fim da narrativa é porque, justamente, ele se recusou a fazer esta escolha. Uma vez que o velho pintor fala de sua Belle Noiseuse, ele utiliza uma linguagem de carne e de sangue; as palavras do amante se sobrepõem àquelas do pintor: "seus olhos me pareciam húmidos, sua carne estava agitada. As tranças de seus cabelos balançavam. Ela respirava"46 (BALZAC, 1981, p. 54). Frenhofer se torna vítima de sua escolha que ele recusou ao querer misturar o amor à arte. Ao contrário de Poussin, amante da modelo Gillette, o velho gênio ultrapassa os limites da arte ao desejar uma paixão cega (e, de acordo com ele, sem risco) ao modo original: "qual amante? [...] ela o trairá cedo ou tarde. A minha me será sempre fiel"47 (BALZAC, 1981, p. 65).

Restam Poussin e Grassou cujas escolhas tomam direções opostas. O jovem Poussin, ao fim do romance, volta-se definitivamente em direção à arte, apesar da imensa beleza de Gillette. Allan Pasco (1991, p. 117) demonstrou que esta diferenciação dolorosa colocada na origem da carreira de Poussin é a razão sine qua non do seu sucesso futuro. É porque o neófito não cometerá jamais o erro de misturar amor e arte (embora trabalhando com os dois) que ele atingirá a genialidade artística.

Quanto à Grassou, ele obtém o sucesso junto à burguesia, justamente por sua escolha ser inversa àquela feita por Poussin. Acaba por aceitar totalmente a condição de artista medíocre e casa-se com a jovem Vervelle, consciente do bom negócio: "Tendo vivido entre o trabalho e a miséria, ele nunca teve tempo para amar"48 (BALZAC, 1977, p. 1102). Esta ausência de paixão lhe impediu o acesso ao dom

\footnotetext{
43 "[...] un air de bonheur qui annonçait en eux un respectable enthousiasme pour les Arts."

44 "[...] pourquoi ne m'avez-vous pas appris les Arts ? [...] puis nous aimons les Arts."

${ }^{45}$ A este respeito, cf. obra de Allan Pasco, Balzacian Montage (p.114).

46 "Ses yeux me semblaient humides, sa chair était agitée. Les tresses de ses cheveux remuaient."

47 "Quelle maîtresse ? répondit Frenhofer. Elle le trahira tôt ou tard. La mienne me sera toujours fidèle !"

48 "Ayant vécu dans le travail et dans la misère, il n'avait jamais eu le temps d'aimer."
} 


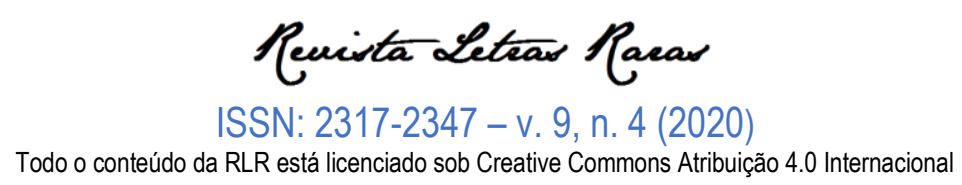

absoluto. Por outro lado, ele pode se consolar aproveitando de suas riquezas materiais que o permitem cercar-se "de verdadeiras obras primas, que não são de sua autoria"49 (BALZAC, 1977, p. 1111).

A oposição entre o genial e o plágio se encontra, igualmente, na essência dos dois romances. Assim, a presença de Poussin em Le Chef-d'œuvre inconnu atesta a genialidade da criação. O narrador introduziu este artista real (cujas obras já são conhecidas do leitor) para antecipar a noção da beleza genial. De outra parte, é importante prestar atenção a seguinte frase de Frenhofer: "Esta tela vale mais que as pinturas do embusteiro Rubens com suas montanhas de carnes flamengas, empoadas de pigmento vermelho, com suas cabeleiras ruivas e onduladas, e sua confusão de cores"50 (BALZAC, 1981, p. 50). ${ }^{51}$ Inocente à primeira vista, a intervenção do velho pintor mostra-se primordial na leitura de Pierre Grassou. De fato, destaca-se que os Vervelle aparecem como "legumes" e que na descrição de Virginie não falta a cabeleira ruiva, nem as cores descritas na citação anterior: "seguia uma jovem aspargo, com seu vestido verde e amarelo, e que mostrava uma cabeça pequena coroada por uma cabeleira divida ao meio e alisada em cada um dos lados, de um amarelo cenoura que um Romano teria adorado"52 (BALZAC, 1977, p. 1103). Enfim, um dos dois quadros mencionados no final do romance não é outro senão Danses de faunes et de nymphes (BALZAC, 1977, p. 1109) de Rubens. As carnes avermelhadas das quais reclama Frenhofer reaparecem em Pierre Grassou na pessoa de Virginie e das ninfas de Rubens.

De outro lado, se Balzac teve que lançar mão de um artista genial à imagem de Poussin para tornar crível a busca de Le Chef-d'œuvre inconnu, teve igualmente que recorrer a um mestre da burguesia para Pierre Grassou, fazendo na pessoa do holandês Gerard Dou. Grassou começa se inspirando fortemente na La Femme hydrophique de Dou (BALZAC, 1977, p. 1100) para finalmente culminar na arte da cópia com, entre outros, o quadro l'Intérieur d'une salle de dissection. Le docteur Tromp faisant sa leçon à ses élèves (BALZAC, 1977, p. 1109) de Rembrandt. Examinando os dois quadros, nota-se a presença, em ambos, de um doutor em ação e o fato de que a obra de Dou foi pintada em 1663, ou seja, após aquela de Rembrandt, que foi terminada em 1632. Sobre este tema, a obra de Wilhem Martin, Gerard Dou se prova muito interessante. Nela se descobre que Gerard Dou foi aluno de Rembrandt em Leyde de 1628 a 1631. Além disso, numerosas semelhanças aparecem entre Dou e

\footnotetext{
49 "[...] de vrais chefs-d'œuvre, qui ne sont pas de lui."

50 "[...] cette toile vaut mieux que les peintures de ce faquin de Rubens avec ses montagnes de viandes flamandes, saupoudrées de vermillon, ses ondées de chevelures rousses, et son tapage de couleurs."

51 Aqui é interessante indicar o extrato de Voyage en Russie de Théophile Gautier: "Apesar do ar bastante vivaz, elas expunham braços robustos, nus até os ombros, bronzeados, coradas e retocadas com aquele rouge que nos assombra nas pinturas de Rubens." cf. o dicionário Le Robert, v.VI, 1970, "vermillon" (784).

52 "Suivait une jeune asperge, verte et jeune par sa robe, et qui montrait une petite tête couronnée d'une chevelure en bandeau, d'un jaune-carotte qu'un Romain eût adore [...]"
} 


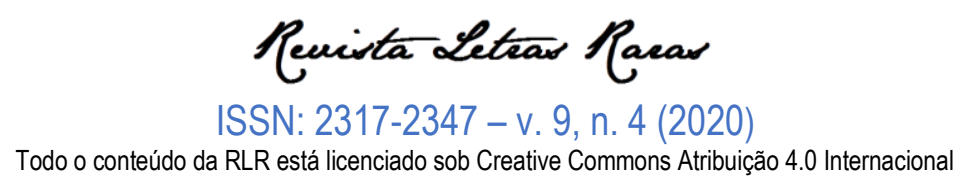

Grassou. O holandês, rapidamente, se especializou em retratos burgueses que ele representava sempre na mesma janela. Martin nos dá assim, informações muito importantes sobre início de carreira de Dou. Descobre-se, então, que o primeiro patrão do pintor, um certo Spiering, não hesitava em se aproveitar da pobreza do artista (MARTIN, 1902, p. 10). Mas, é sobretudo a descrição do mercado de Arte de Leyde que parece desvelar o plano do romance de Balzac:

[he] went to see M. de Bye [...] since he had "a great many pictures by Dou." M. de Bye was an amateur and collector, who was also a dealer. There were many men of this type at the time; every Dutchman who owned a picture was ready to part whit it for a sufficient sum. ${ }^{53}$ (MARTIN, 1902, p. 10)

Enfim, o personagem de Elias Magus parece muito com o de Gerrit Hylenburch que "was [...] certainly fraudulent; he not only employed 'young artists to copy pictures,' but he passed off the copies as originals"54 (MARTIN, 1902, p. 11).

Se tomarmos por apreendidas as similitudes que existem entre La leçon du docteur Tromp e La Femme hydrophique, pode-se então afirmar que Pierre Grassou segue uma hierarquia do plágio que ele mesmo definiu. Ele começa por uma reprodução dissimulada de Dou, o copista, para alcançar uma realização perfeita de Rembrandt, o copiado.

Em Le Chef-d'œuvre inconnu Frenhofer se aproxima do ideal absoluto graças a sua própria criação artística. Mas esta busca desmedida o faz perder contato com a razão e com a realidade, ainda que ele acabe convencido de sua superioridade. Sua monomania o conduz a espirais devastadoras que provocarão sua própria destruição ao fim do romance.

Pierre Grassou, por sua vez, se consagra à arte da copia que ele terminou por aceitar. A despeito do ideal, ele refaz a hierarquia do plágio, na qual ele consegue se impor como mestre absoluto. Ele desfruta de sua popularidade no seio da burguesia mesmo sofrendo de sua mediocridade artística, a qual ele nunca poderá apagar.

Portanto, Pierre Grassou não dá mais a imagem deste agradável entretenimento escrito numa turbulência. Este romance se insere perfeitamente em $A$ Comédia humana graças às suas características de retrato social. Longe de permanecer em seu estilo caricatura, o texto frequentemente negligenciado desenvolve uma verdadeira problemática da condição do artista no seio da sociedade (burguesa) que o cerca. Ao escrever Pierre Grassou como oposição, ou mesmo uma "desconstrução" de Le Chef-d'œuvre

\footnotetext{
53 "[ele] foi ver M. de Bye [...] uma vez que ele tinha 'muitos quadros de Dou'. M. de Bye era um colecionador amador, mas também um negociante. Havia muitos como ele na época. Cada holandês que possuía um quadro estava pronto a se desfazer do mesmo, desde que por uma boa quantia."

54 "foi certamente fraudador, pois além de empregar 'jovens artistas para copiar quadros', ele os fazia passar por originais."
} 


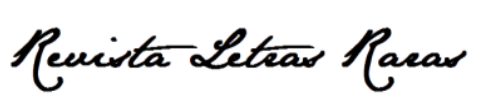

ISSN: 2317-2347 - v. 9, n. 4 (2020)

Todo o conteúdo da RLR está licenciado sob Creative Commons Atribuição 4.0 Internacional

inconnu, Balzac quis denunciar o poder burguês, no qual a ausência de gosto, misturada a um espírito "novo rico", produzem artistas-comerciantes, eliminando a genialidade criativa.

\section{Referências}

BALZAC, H. A obra-prima desconhecida. Tradução de Leila de Aguiar Costa. In: DIDIHUBERMAN, Georges. A pintura encarnada. São Paulo: Escuta, 2012.

BALZAC, H. A obra-prima ignorada. In: A comédia humana. Vol XV. Introduções, notas e orientação: Paulo Rónai. Porto Alegre: Globo,1959a. p. 387-412.

BALZAC, H. A obra-prima ignorada. Tradução de Teixeira Coelho. São Paulo: lluminuras, 2012a.

BALZAC, H. A procura do absoluto. In: BALZAC, Honoré de. A comédia humana. Vol XV. Introduções, notas e orientação Paulo Rónai. Porto Alegre: Globo, 1959b. p. 415-469.

BALZAC, H. Gambara. In: BALZAC, H. La comédie humaine. Vol. 10. Ed.Pierre-Georges Castex. Bibliothèque de la Pléiade. Paris: Gallimard, 1979. p.459-516.

BALZAC, H. Gambara. In: BALZAC, Honoré de. A comédia humana. Vol XV. Introduções, notas e orientação Paulo Rónai. Porto Alegre: Globo, 1959c. p. 473-633.

BALZAC.H. La Comédie humaine. Paris: Arvensa Editions, 2012. Ebook Kindle Edition.BALZAC, H. La Recherche de l'absolu. Ed. S. de Sacy. Paris: Gallimard, 1976.

BALZAC, H. Le chef-d'-œuvre inconnu. Ed. Marc Eigeldinger. Paris: Garnier-Flamarion, 1981.

BALZAC, H. Pierre Grassou. In: BALZAC, H. La comédie humaine. Vol. 6. Ed.Pierre-Georges Castex. Bibliothèque de la Pléiade. Paris: Gallimard, 1977. p.1091-1111.

BARDĖCHE, M. Introduction. Pierre Grassou. In: BALZAC, H. CEuvres complètes . Vol. 4. Paris: CHH, 1969. p.69-72.

BEEBE, M. "The Lesson of Balzac's artist". Criticism v.2, n.3, p. 221-241, 1986.

BESSER, G. Balzac's concept of Genius. Genève: Droz, 1969.

BONARD, O. La Peinture dans la création balzacienne. Genève: Droz, 1969.

MARTIN, W. Gerard Dou. London: George Bell and sons, 1902.

MASSOL-BÉDOIN, C. L'Artiste ou l'imposture: le secret du 'Chef-d'œuvre inconnu' de Balzac. Romantisme, Paris, v.16, n. 54.4, p. 44-47, 1986.

MEININGER, A-M. Introduction. "Pierre Grassou". In: BALZAC, H. La Comédie humaine. Vol. 6. Ed. Pierre-Georges Castex. Bibliothèque de la Pléiade. Paris: Gallimard, 1977. p.1079-1089

PASCO, A. H. Balzacian montage. Configuring La Comédie humaine. Toronto: Toronto University Press, 1991.

WURMSER, A. La Comédie inhumaine. Paris: Gallimard, 1970. 